\title{
Sol-gel processing: A versatile concept for special glasses and ceramics
}

\author{
D GANGULI \\ Sol-Gel Laboratory, Central Glass and Ceramic Research Institute, Calcutta 700032, India
}

\begin{abstract}
The various parameters related to sol-gel processing are discussed with special reference to those which usually attract less attention but depending on the final product in mind, can play important roles. The versatility of the sol-gel technique in materials preparation is demonstrated by discussing the various products developed at the author's laboratory by using this processing method.
\end{abstract}

Keywords. Sol-gel processing; silica glass; optical coatings; spherical oxide powders; oxide fibres.

\section{Introduction}

Sol-gel processing has become almost a by-word in modern inorganic and organicinorganic hybrid material development because of its simplicity and effectiveness. A wide range of new and known materials have been successfully prepared in recent times with some advantage using this technique (Mackenzie 1988; Ganguli 1989; Schmidt 1989). What started with various recipés of material preparation in a few European countries several decades ago has now bloomed into a valid commercial proposition in many cases, backed by bits of theory which are now falling into place to generate a coherent picture.

In spite of this phenomenal development, preparation of materials via sol-gel processing continues to be dependent on mastery in chemical experimentation; as a result, a good understanding of the experimental designs and control over various processing parameters remains an essential prerequisite of success.

The present article discusses (i) various processing parameters in sol-gel developmental work which are often not taken care of, or at least not adequately controlled, and (ii) the various products developed by sol-gel processing at CGCRI, indicating thereby the versatility of the technique.

\section{Aspects of processing}

\subsection{The respected and neglected parameters}

From the practical point of view, sol-gel processing can be defined broadly by a series of experimental steps, as shown below.

(i) Preparation of a sol, generally by in situ generation of ultrafine particles in a liquid vehicle (via growth of polymeric molecules or Ostwald ripening).

(ii) Ageing of the sol at a suitable temperature for arriving at desired properties (e.g. optimum viscosity). 
Table 1. Various parameters in sol-gel processing.

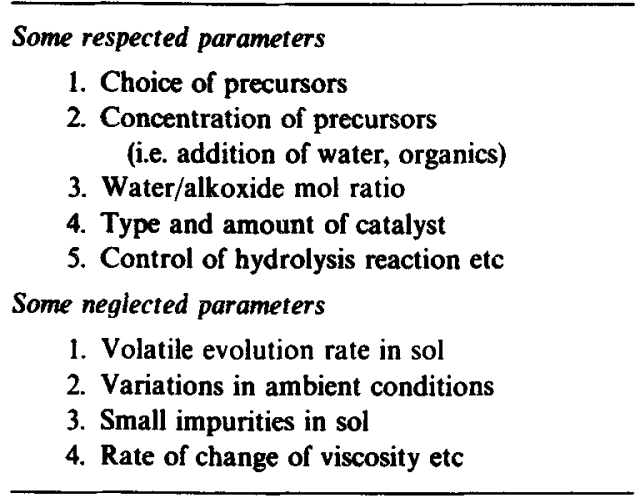

(iii) Casting, spinning, drawing, coating, emulsification etc of the sol for obtaining the required gel form via sol-gel transition.

(iv) Drying, followed by heating in most cases, to obtain the desired product.

Each such step, again, is guided by a set of experimental parameters which control the chemistry of the process and the quality of the final product. For ensuring reproducibility of the final product, all such parameters must be given due attention. Obviously, this becomes extremely important when commercial exploitation of a sol-gel preparative process is in view.

The innumerable recipés in the world literature discussed in a recent book by Brinker and Scherer (1990) have led to the recognition of some of these experimental parameters to be important specially in defining the quality of a sol, and consequently, that of the corresponding gel. There are, on the other hand, several parameters probably demanding lesser attention which can also affect the properties of the sol and gel, and thus, put their unmistakable signature on the properties of the generated products. Accordingly, in table 1, the parameters have been divided into two categories: the respected and the neglected ones.

Extensive studies have been made on the roles of the 'respected' parameters of table 1 ; in fact, manipulation of the starting sols and hence the final products by controlling these parameters is an essential part of sol-gel processing. We shall therefore confine ourselves to the 'neglected' parameters and their effects. A larger part of the modern investigations is based on "polymeric" sols obtained from different alkoxides as starting material (Brinker and Scherer 1990), and hence, the present discussion is rather biased in that direction.

\subsection{Volatile evolution rate in sols}

While growth of particles in a sol via extensive polymerization or Ostwald ripening (or both) leads to progressive proximity of the particles and final contact resulting in network formation and gelation, evaporation of the liquid vehicle in a sol serves in effect the same purpose. The gelling time of a sol thus is an indication of the rate at which the (growing) particles come into contact with each other and the type of network that is formed as a result. During the sol-gel transition period, the volatile 


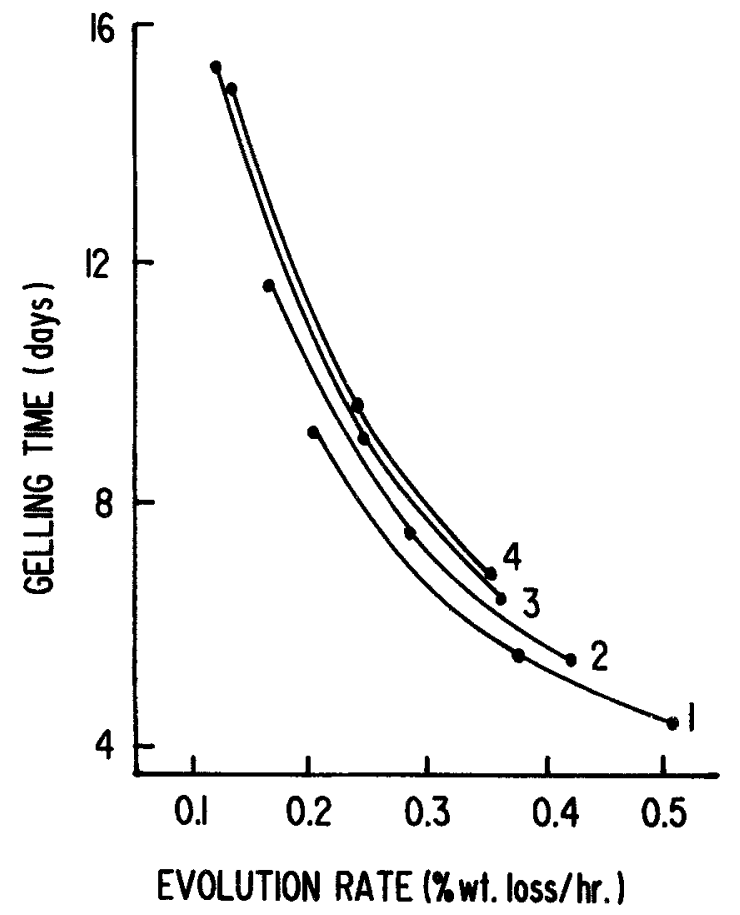

Figure 1. Effect of volatile evolution rate on gelling time of a tetraethyl orthosilicate (TEOS) derived sol. Solutions prepared at $\mathrm{HCl} / \mathrm{TEOS}=\mathbf{0 . 0 3}$ (molar) and $\mathrm{CH}_{3} \mathrm{OH} / \mathrm{TEOS}$ volume ratio $=1$ with the following $\mathrm{H}_{2}$ O/TEOS molar ratios: (1) 5 ; (2) 10 ; (3) 15 and (4) 20 . After Kundu and Ganguli (1986).

liquid is usually allowed to escape in a "controlled" way, but the effect of this on the process of gelation and the nature of gels thus obtained often escapes the attention of the researcher.

Figure 1 (Kundu and Ganguli 1986) shows the effect of controlled evolution of the volatile liquid (a solution of the added water and methanol, as also ethanol released during the hydrolysis of silicon ethoxide) from a 'silica' sol on the gelling time. An inverse relationship is expected and indicates that with a suitably high volatile evolution rate, an almost instantaneous gelation may not be ruled out. Figure 2 shows how the volatile evolution rate in the sol controls the bulk density of the obtained porous glass. Such results make it clear that gels or densified gels of required porosity and surface area can be selectively synthesized simply by keeping a control on the volatile evolution rate.

\subsection{Ambient temperature during sol-gel transition}

The progress in various chemical reactions in a sol leading to the ultimate sol-gel transition is known to be closely related to factors like ambient temperature and humidity, specially the former. Humidity is important specially for low-water compositions, as it can cause uncontrolled hydrolysis of partially hydrolysed alkoxides (e.g. those of $\mathrm{Ti}$ and $\mathrm{Zr}$ ) in solution. 


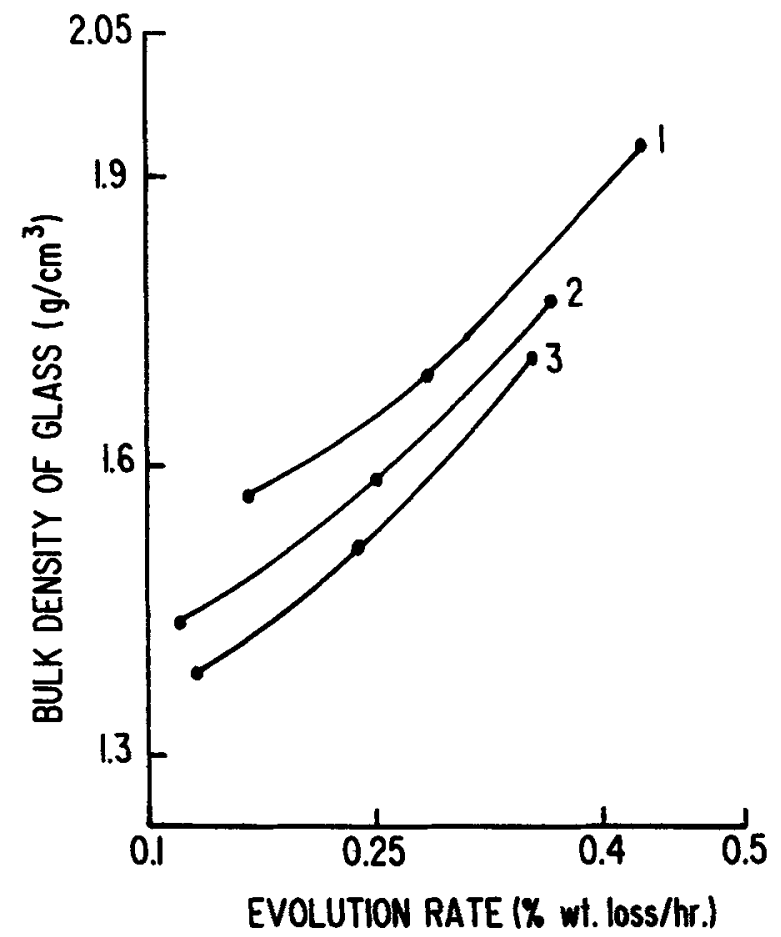

Figure 2. Variations of bulk density of densified $\left(700^{\circ} \mathrm{C}\right)$ gel with volatile evolution rate. Numbers 1, 2 and 3 assigned to the curves correspond to the numbers 2, 3 and 4 respectively of figure 1. After Kundu and Ganguli (1986).

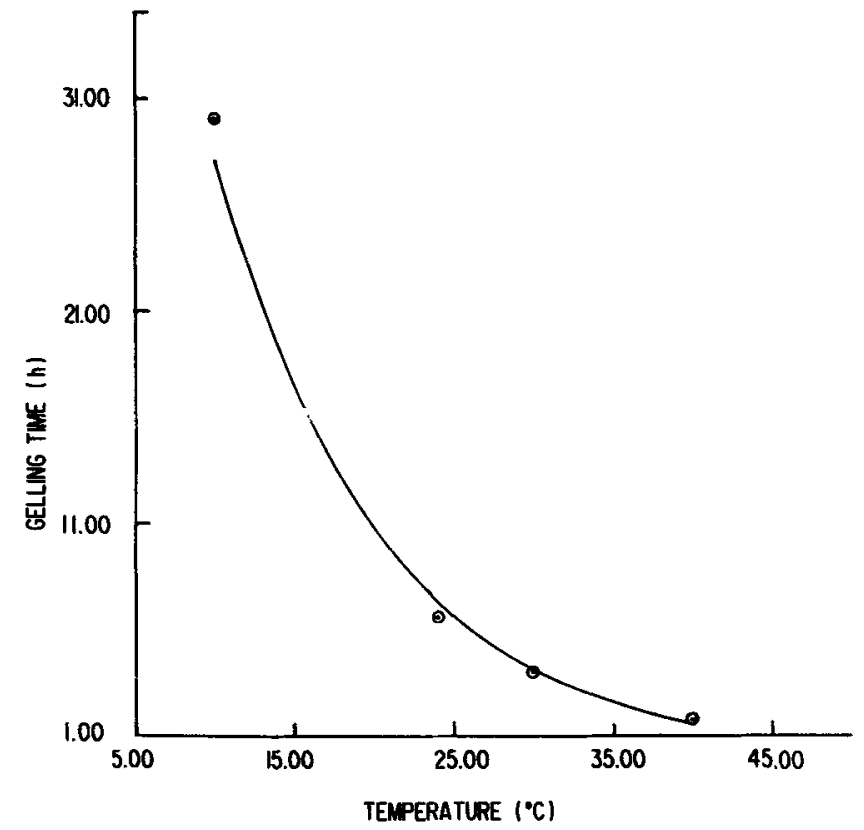

Figure 3. Effect of ambient temperature on gelling time of a tetraethyl orthosilicate derived sol. Data from Patra (1992). 
As regards temperature, a scan of the relevant literature shows that while the effect of elevated temperatures on gelling time and gel properties has been studied in some detail (Colby et al 1986), the role of minor shifts in the ambient temperature has remained rather unexplored. Note that the exact time required for the sol-gel transition in a system is a very important aspect of processing, as this determines the working time i.e. for casting etc of the sol, as indicated earlier. The gelling time is also known to be linked with the structure of the product (Colby et al 1986; Yamane 1988). For ensuring reproducibility, therefore, the ambient conditions also have to be closely monitored. Figure 3 shows the significant difference in gelling time of a silicon ethoxidederived sol that may take place with relatively minor changes in the ambient temperature (compare seasonal fluctuations of temperature in a given region in India).

\subsection{Effect of impurity ions}

Early work in the beginning of the twentieth century and later (Dienert and Wandenbulcke 1924; Hurd et al 1958) showed that the gelling time of sodium silicatederived silica sols could be significantly changed by addition of alkali and alkaline earth cations, and anions like $\mathrm{Cl}^{-}$and $\mathrm{NO}_{3}^{-}$.

Recent work (Bansal 1990; Patra and Ganguli 1992a; Patra 1992) has thrown further light on this phenomenon, and models have been suggested to explain why some cations increase the gelling time while others cause a decrease. This phenomenon is specially important for colloidal aquosols prepared via inorganic salts where trace ionic impurities are often detected, or for alkoxide-derived precursor sols for multicomponent oxide products. In any case, the effect can be drastic with certain impurities (Patra and Ganguli, 1992a; Pope and Mackenzie 1986), e.g. 1 equivalent mol\% PbO in a silica sol can cut down the gelling time from $30 \mathrm{~h}$ to $2.5 \mathrm{~h}$ and 0.05 mole of $\mathrm{HF}$ in a mole of silicon ethoxide can cause a decrease from $1000 \mathrm{~h}$ to only $12 \mathrm{~h}$.

\subsection{Change in viscosity with time}

Another important factor which has been studied in detail (Sakka and Kamiya 1982; Debsikdar 1986) but has not always been considered while formulating a process for the preparation of materials (e.g. coatings on glass) from a bulk sol as a continuous activity, is the progressive increase in viscosity of a sol during its journey towards the gelling point. Figure 4 shows how the thickness of a coating of amorphous silica can change with increase in viscosity of the system (Strawbridge and James 1986). It is obvious that for a given lifting speed in a dip coating system, a rise in viscosity of the sol with time can cause significant changes in the coating thickness which, specially in case of various optical applications, cannot be tolerated.

For keeping the viscosity of the sol stable and constant for reasonably long periods of time, several chemical methods have been used. Such methods are mostly based on the substitution of the functional groups of alkoxides with non-reactive or less reactive groups. Thus, methoxy- or ethoxy-groups have been substituted by methyl groups, or chelating agents like acetylacetone have been employed to slow down the progress of hydrolysis.

While the progressive rise in viscosity with time is a hindering factor for continuous use of a bulk sol, the phenomenon is indeed important for understanding the structurally 


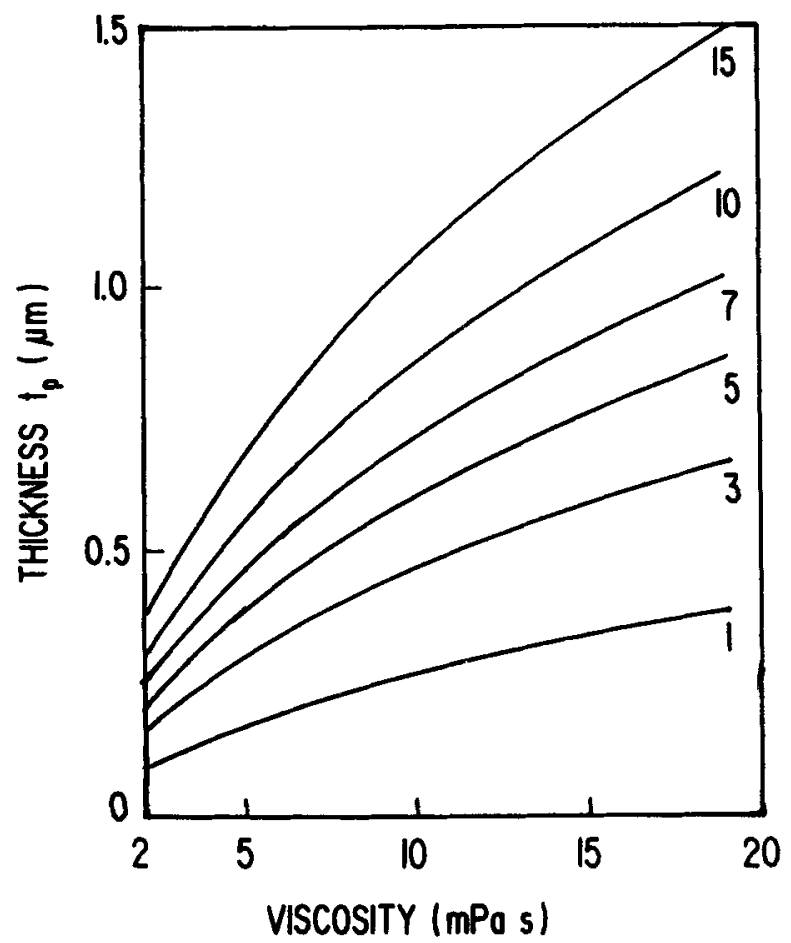

Figure 4. Effect of viscosity on the thickness of densified silica coatings prepared from an alkoxide-derived sol by the dipping technique. The numbers of the curves indicate lifting speeds (cm/min) of the dip coating system. After Strawbridge and James (1986).

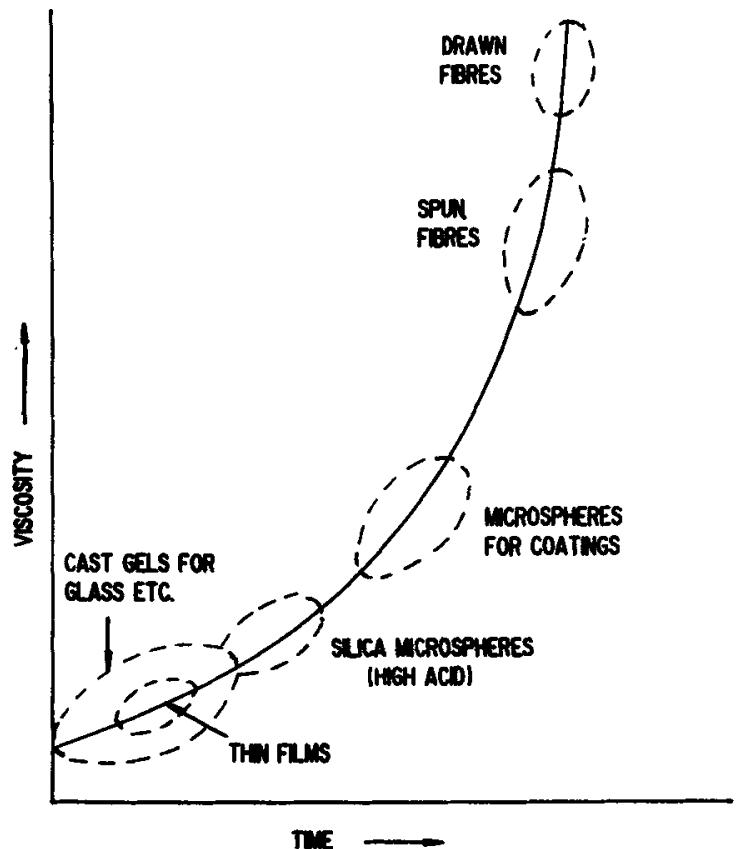

Figure 5. Schematic diagram showing the viscosity-time curve of a hypothetical sol and the relative viscosity regimes for obtaining different gel shapes. 
different precursors that are generated in the process and using them suitably. The point here is that for different materials, processing of the sol for obtaining a particular gel form usually starts at different points in its progress towards the sol-gel transition, i.e. at different viscosities. Thus while casting for monolithic gel/glass formation is done almost immediately after the formation of the sol, i.e. at the lowest viscosity, a hand-drawn fibre is obtained at a viscosity very close to the gel point. A schematic diagram (figure 5) shows some examples.

\section{Sol-gel research at CGCRI}

Keeping the above factors in mind, a number of different materials have been developed at CGCRI by using sol-gel techniques that take care of the point of reproducibility of the end product. A list of the more important areas of activity is given in table 2. Some of the processes thus developed have been transferred to the industry for production, while some others are expected to be similarly utilized in the near future. The so-called "anti-glare" coating is one such area where an amorphous zirconia layer acts as the host for evenly distributed transition metal oxide nanoparticles; this gives the coating specific transmission properties, specially in the ultraviolet and visible ranges (Kundu et al 1989a). Two-layer $(2+2)$ antireflective coatings on ophthalmic lenses yielding up to $99.5 \%$ transmission at around $550 \mathrm{~nm}$ is another area in which a sol-gel process is awaiting transfer to the industry (Biswas et al 1991). Various other coatings have been developed using multilayer designs (Atta et al 1990, 1991; Biswas et al 1987; Kundu et al 1989b), while semiconductor nanocrystals have been successfully doped by using an in situ deposition method in amorphous titania coating (Atta et al 1992).

The advances in the development of sol-gel optical quality silica glass at $\mathbf{R} \& \mathbf{D}$ centres of several multinational companies are now well-known (Rabinovich 1989). Following a sol-gel route with hybrid precursors, high purity, almost hydroxyl-free silica glasses comparable to commercial high purity silica glass have been produced

Table 2. Areas of sol-gel material development at CGCRI.

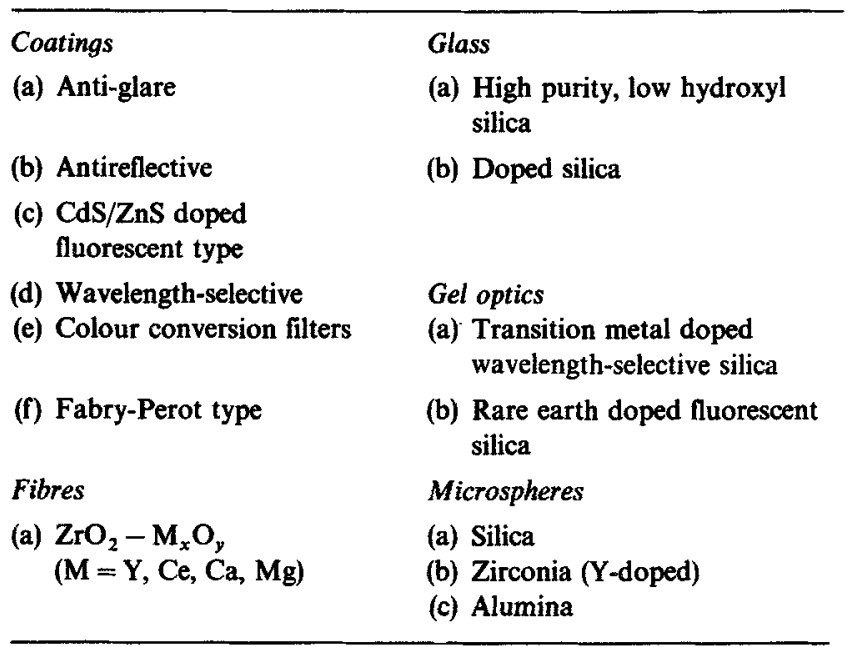


Table 3. Some basic physical properties of the clear silica glass prepared at CGCRI.

\begin{tabular}{ll}
\hline $\begin{array}{l}\text { 1. Thermal expansion coeflicient } \\
\left(\mathrm{cm} / \mathrm{cm} /{ }^{\circ} \mathrm{C}\right)\end{array}$ & $\begin{array}{l}: 4.36 \times 10^{-7} \\
\left(30-1200^{\circ} \mathrm{C}\right)\end{array}$ \\
$\begin{array}{l}\text { 2. Vicker's microhardness } \\
\left(\mathrm{kg} / \mathrm{mm}^{2}\right)\end{array}$ & $: 720-800$ \\
$\begin{array}{l}\text { 3. Visible transmission }(\%) \\
(400-800 \mathrm{~nm})\end{array}$ & $: 93-94$ \\
4. (i) UV cut-off* & $: 210-225$ \\
$\begin{array}{l}(50 \% \text { transmission at, } \mathrm{nm}) \\
\text { (ii) Transmission }(\%) \text { at }\end{array}$ & $: 25-75^{* *}$ \\
$200 \mathrm{~nm}$ & $: 2 \cdot 20$ \\
5. Density (g/cm $\left.{ }^{3}\right)$ & $: 1.462$ \\
6. Refractive index $\left(n_{d}\right)$ & $: 0-30$ \\
7. OH impurity $(\mathrm{ppm})^{* * *}$ & \\
\hline
\end{tabular}

* depends upon sample thickness

$* * 25 \%$ for $3.5 \mathrm{~mm}$ and $75 \%$ for $0.25 \mathrm{~mm}$ thick samples

***measured by FTIR spectroscopy

at CGCRI (Kundu et al 1992; De et al 1993), and commercial utilization of the process is in the offing. Some of the properties of the sol-gel silica glass developed at CGCRI are presented in table 3.

Silica gel monoliths or their thermal derivatives which have not been processed for gel-glass conversion have also proved to be important candidate materials for a variety of optical filters, fluorescent optics etc when doped with suitable cations (rare earth ion, first transition metal ions). Efforts are on at CGCRI in this area (Patra 1992; Patra and Ganguli 1992b; Roy and Ganguli 1992, 1993).

A different area in which sol-gel processing has been shown to yield rich dividends in terms of properties and performance is monodispersed spheres of different oxides in different size ranges. While submicron spherical particles of silica (Chatterjee and Ganguli 1986) have proved to be an interesting material for various inorganic and biomedical applications, glasslike particles of larger size (30-40 micron or larger) have been already synthesized by a new chemical method (Karmakar et al 1991). Further, polycrystalline spheres of doped zirconia and pure alumina, eminently suitable as precursors for plasma-sprayed coatings, have also been developed and the performance demonstrated (Chatterjee et al 1993; Joshi et al 1993) in case of the latter. Detailed work on several plasma-sprayable powders is now in progress in collaboration with the industry.

Sol-gel derived partially or fully stabilized zirconia fibres are relatively new candidates in the area of advanced ceramics as reinforcement or high temperature insulation material (Marshall et al 1987; Kamiya et al 1991). Intensive investigations have been carried out at CGCRI in this line with zirconium alkoxides (e.g. De et al 1990; Chatterjee et al 1992a), but currently the interest has shifted to oxychloridederived acetate sols for the sake of process economy (Chatterjee et al 1992b).

The above brief account is probably adequate to show that sol-gel processing is indeed a versatile method of preparation of a wide array of materials, and if exploited properly, can yield globally competitive technology for not only efficient known materials, but also new materials with unexpected properties. 


\section{Acknowledgement}

The author is grateful to his colleagues of the Sol-Gel Laboratory, CGCRI for their teamwork in making sol-gel research a pleasurable pursuit.

\section{References}

Atta A, Biswas P K and Ganguli D 1990 J. Non-Cryst. Solids 125202

Atta A, Biswas P K and Ganguli D $1991 \mathrm{~J}$. Mater. Sci. Lett. 10466

Atta A, Biswas P K and Ganguli D 1992 Mater. Lett. 1599

Bansal N P 1990 J. Am. Ceram. Soc. 732647

Biswas P K, Kundu D and Ganguli D 1987 J. Mater. Sci. Lett. 61481

Biswas P K, Atta A and Ganguli D 1991 Proc. 18th Optical Soc. India, Kodaikanal Observatory Bull. (ed) A K Saxena 1177

Brinker C J and Scherer G W 1990 Sol-gel science: the physics and chemistry of sol-gel processing (San Diego: Academic Press)

Chatterjee M and Ganguli D 1986 Trans. Indian Ceram. Soc. 4595

Chatterjee M, Chatterjee A and Ganguli D 1992a Ceram. Int. 1843

Chatterjee M, Naskar M K and Ganguli D 1992b Indian Patent Application No. 805/DEL/92

Chatterjee M, Ray J, Chatterjee A, Ganguli D, Joshi S V and Srivastava M P 1993 J. Mater. Sci. 282803

Colby M W, Osaka A and Mackenzie J D 1986 J. Non-Cryst. Solids 8237

De G, Chatterjee A and Ganguli D 1990 J. Mater. Sci. Lett. 9845

De G, Kundu D, Karmakar B and Ganguli D 1993 Mater. Lett. 16231

Debsikdar J 1986 Adv. Ceram. Mater. 193

Dienert F and Wandenbulcke 1924 Comp. Rend. 178564

Ganguli D 1989 Indian J. Phys. A63 253

Hurd C B, Rhoades J W, Gormley W G and Santora A C 1958 J. Phys. Chem. 62882

Joshi S V, Srivastava M P, Chatterjee M, Ray J, Chatterjee A and Ganguli D 1993 Bull. Mater. Sci. 1619

Kamiya K, Takahashi K, Maeda T and Nasu H 1991 J. Europ. Ceram. Soc. 7295

Karmakar B, De G, Kundu D and Ganguli D 1991 J. Non-Cryst. Solids 13529

Kundu D and Ganguli D 1986 Collected Papers, XIV International congress on glass (Calcutta: Indian Ceramic Society) 1141

Kundu D, Biswas P K and Ganguli D 1989a Glastech. Ber. 62244

Kundu D, Biswas P K and Ganguli D 1989b J. Non-Cryst. Solids 11013

Kundu D, De G, Karmakar B, Patra A and Ganguli D 1992 Bull. Mater. Sci. 15453

Mackenzie J D 1988 J. Non-Cryst. Solids 100162

Marshall D B, Lange F F and Morgan P D $1987 \mathrm{~J}$. Am. Ceram. Soc. 70 c-187

Patra A 1992 Preparation and characterization of pure and doped silica by sol-gel processing, Ph. D. thesis, Jadavpur University, Calcutta

Patra A and Ganguli D 1992a J. Non-Cryst. Solids 139165

Patra A and Ganguli D 1992b J. Mater. Sci. Lett. 12116

Pope E J A and Mackenzie J D 1986 J. Non-Cryst. Solids 87185

Rabinovich E M 1989 in Sol-gel science and technology (eds) M A Aegerter, M Jafelicci Jr, D F Souza and E D Zanotto (Singapore: World Scientific) pp 375-401

Roy S and Ganguli D 1993 Mater. Lett. 16352

Roy S and Ganguli D 1993 Mater. Lett. (accepted for publication)

Sakka S and Kamiya K 1982 J. Non-Cryst. Solids 4831

Schmidt H 1989 in Sol-gel science and technology (eds) M A Aegerter, M Jafelicci Jr, D F Souza and E D Zanotto (Singapore: World Scientific) pp 432-469

Strawbridge I and James P F 1986 in Br. Ceram. Proc. 38 (ed) R W Davidge (Stoke-on-Trent: The Institute of Ceramics) pp 251-262

Yamane M 1988 in Sol-gel technology for thin films, fibres, preforms, electronics and speciality shapes (ed) L C Klein (New Jersey: Noyes Publications) pp 200-225 